\title{
Incidence of fistula after primary cleft palate repair: a 25-year assessment of one surgeon's experience
}

\author{
Min Suk Park ${ }^{1}$, Hyung Joon Seo ${ }^{1,2}$, Yong Chan Bae $e^{1,2}$ \\ ${ }^{1}$ Department of Plastic and Reconstructive Surgery, Pusan National University School of Medicine, Busan; ${ }^{2}$ Biomedical Research Institute, \\ Pusan National University Hospital, Busan, Korea
}

\begin{abstract}
Background Cleft lip and cleft palate are the most frequent congenital craniofacial deformities, with an incidence of approximately 1 per 700 people. Postoperative palatal fistula is one of the most significant long-term complications. This study investigated the incidence of postoperative palatal fistula and its predictive factors based on 25 years of experience at our hospital.

Methods We retrospectively reviewed 636 consecutive palatal repairs performed between January 1996 and October 2020 by a single surgeon. Data from patients' medical records regarding cleft palate repair were analyzed. The preoperative extent of the cleft was evaluated using the Veau classification system, and the cleft palate repair technique was chosen according to the extent of the cleft. SPSS version 25.0 was used for all statistical analyses, and exploratory univariate associations were investigated using the t-test.

Results Fistulas occurred in 20 of the 636 patients; thus, the incidence of palatal fistula was $3.1 \%$. The most common fistula location was the hard palate $(9 / 20,45 \%)$, followed by the junction of the hard and soft palate $(6 / 20,30 \%)$ and the soft palate $(5 / 20,25 \%)$. The cleft palate repair technique significantly predicted the incidence of palatal fistula following cleft palate repair $(P=0.042)$. Fistula incidence was significantly higher in patients who underwent surgery using the Furlow double-opposing Z-plasty technique (12.1\%) than in cases where the Busan modification (3.0\%) or two-flap technique (2.0\%) was used.

Conclusions The overall incidence of palatal fistulas was 3.1\% in this study. Moreover, the technique of cleft palate repair predicted fistula incidence.
\end{abstract}

Keywords Cleft palate / Palate surgery / Oral fistula / Risk factor

Received: July 4, $2021 \bullet$ Revised: September 24, $2021 \bullet$ Accepted: October 18, 2021

pISSN: 2234-6163 • elSSN: 2234-6171 • https://doi.org/10.5999/aps.2021.01396• Arch Plast Surg 2022;49:43-49
Correspondence: Yong Chan Bae Department of Plastic and Reconstructive Surgery, Pusan National University Hospital, Pusan National University School of Medicine, 179 Gudeok-ro, Seo-gu, Busan 49241, Korea

Tel: +82-51-240-7269

Fax: +82-51-243-9405

E-mail: baeyc2@hanmail.net

\section{INTRODUCTION}

Cleft lip and cleft palate are the most frequently occurring congenital craniofacial deformities, with an incidence of approximately 1 per 700 people $[1,2]$. The goal of cleft palate surgery is to divide the nasal and oral cavities, maintain normal velopharyngeal function, and minimize restricted postoperative facial growth $[3,4]$.

Possible postoperative complications of cleft palate repair include bleeding, wound dehiscence, palatal fistula, velopharyngeal insufficiency, and facial growth retardation [5]. Postoperative palatal fistula is one of the most significant long-term complications. Palatal fistula occurs when the primary surgical repair of the palate breaks down or healing fails, and it induces hyper- 
nasal speech, articulation disorders, and nasal regurgitation of food and drink $[6,7]$.

The incidence of palatal fistula following cleft palate repair was reported to be $0 \%-60 \%$ historically and $3 \%-35 \%$ in recent studies [8-12]. Furthermore, many factors, including the surgical technique, timing of surgery, extent of cleft, presence of cleft lip, surgeon's experience, and associated syndromes, are known to increase the risk of palatal fistula $[12,13]$.

This study aimed to evaluate the incidence of postoperative palatal fistula and its predictive factors based on a surgeon's 25 year experience at our hospital. Thus, we evaluated patients' sex, age at cleft palate repair, the presence of cleft lip and associated syndromes, the extent of the cleft, and the technique of cleft palate repair. We attempted to broaden the understanding of palatal fistula following primary cleft palate repair by determining the incidence of palatal fistula and predictive factors.

\section{METHODS}

We retrospectively reviewed 636 consecutive cleft palate repairs performed at our hospital between January 1996 and October 2020 by a single surgeon (YCB). Patients with associated syndromes and those with submucous cleft palate were included. Cases where surgery was performed by a different surgeon and patients with incomplete medical records or inadequate followup (less than 6 months) were excluded.

The following data were obtained from 636 medical records and analyzed: the presence of a palatal fistula following cleft palate repair and location, the differences in its incidence according to sex, age at the time of cleft repair, presence of a syndrome, cleft lip, extent of cleft, and technique of cleft palate repair. We also analyzed the statistical significance of differences in the incidence of palatal fistula according to the technique of cleft palate repair.

The preoperative extent of the cleft was evaluated using the Veau classification system, as follows: Veau class I, cleft soft palate; Veau class II, hard/soft cleft palate; Veau class III, unilateral cleft lip/palate; and Veau class IV, bilateral cleft lip/palate [14].

Palatal fistula was defined as a patency forming and persisting for 6 months or longer after surgery between the oral and nasal cavities, as a result of breakdown or failure of healing in the primary surgical repair site at the cleft palate (Fig. 1). The location of the fistula was classified using the Pittsburgh classification [15].

\section{Choice of surgical technique}

Primary cleft palate repair was performed when patients were approximately 12 months of age. However, there were cases in

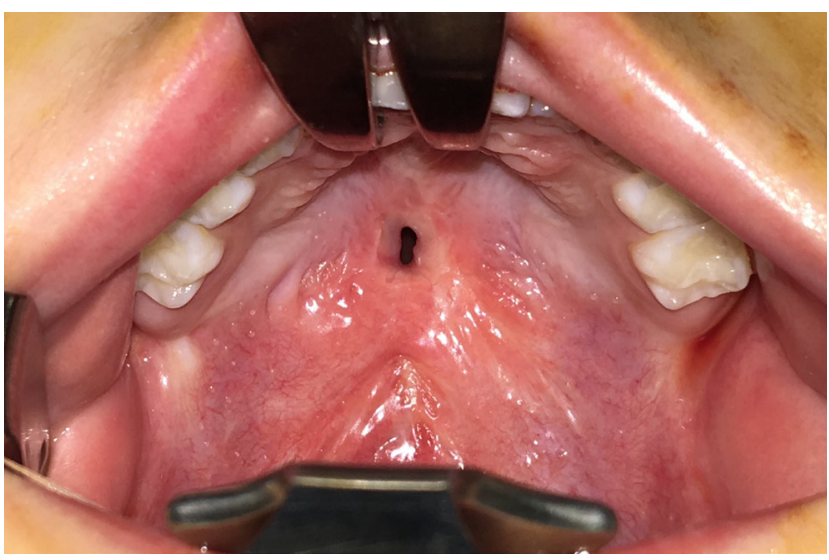

Fig. 1. Postoperative palatal fistula on the hard palate in a 3-yearold patient.

which repair was postponed due to a delayed diagnosis or other medical issues. For patients with submucous cleft palate, cleft palate repair was performed in those diagnosed with an articulation disorder by a language pathologist.

The cleft palate repair technique was chosen depending on the extent of the cleft to ensure adequate tissue mobilization and maximize vascularity. In the very early stage, cleft palate repair was carried out using the Veau-Wardill-Kilner technique or intravelar veloplasty. For submucous cleft palate, cleft repair was performed using Furlow double-opposing Z-plasty [4]. In most cases of Veau classes I and II, cleft palate repair was performed using the modified cleft palate repair method (Busan modification) [16]. Cases of Veau classes III and IV were repaired using two-flap repair, and the anterior nasal mucosa was closed using a vomer turnover flap.

The modified cleft palate repair method (Busan modification) [16] is a modified two-flap palatoplasty that omits an anterior V-shaped incision. It involves performing a halving incision along the cleft margin and a lateral relaxing incision on both sides along the alveolar margin (Fig. 2). It also involves conducting a radical muscle dissection of the abnormally inserted levator muscle from the nasal-side mucosa and oral-side mucosa, followed by retrorepositioning of the levator muscle in its anatomical position and reconstruction of the levator muscle by making a levator sling.

\section{Statistical analysis}

SPSS version 25.0 (IBM Corp., Armonk, NY, USA) was used for all statistical analyses. The t-test was used to investigate exploratory univariate associations with variables including sex, age at cleft palate repair, cleft lip, associated syndrome, extent of cleft, and technique of cleft palate repair to identify predictive factors associated with the incidence of palatal fistula. In addi- 


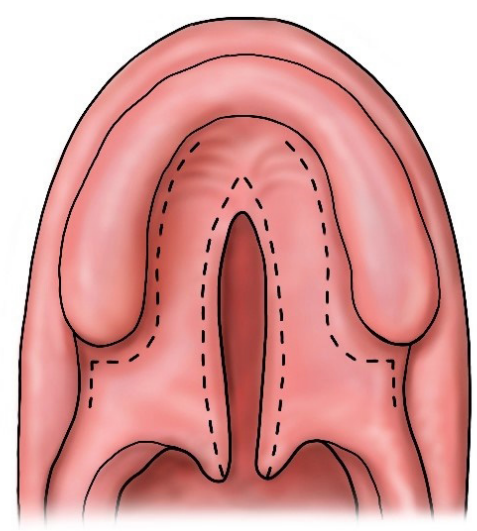

Fig. 2. Design of the Busan modification. A halving incision is performed along the cleft margin, and a lateral relaxing incision is performed on both sides along the alveolar margin. The levator muscle is placed in its anatomical position and a levator sling is created.

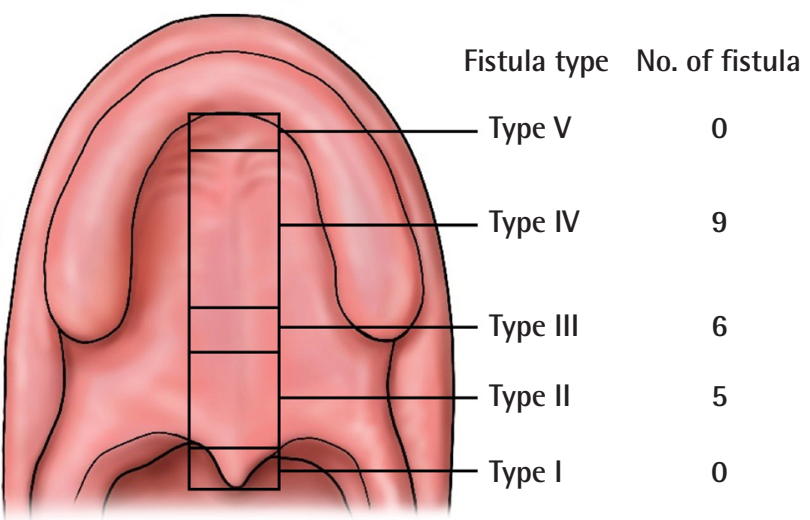

Fig. 3. Location of postoperative palatal fistulas according to the Pittsburgh fistula classification (type I, bifid uvula; type II, soft palate; type III, junction of the hard and soft palate; type IV, hard palate; type $\mathrm{V}$, junction of the primary and secondary palates).

tion, we analyzed the statistical significance of the differences in outcomes between different techniques of cleft palate repair. Statistical significance was set at $\mathrm{P}<0.05$.

\section{RESULTS}

The total study population comprised 636 patients. Fistulas occurred in 20 patients (Table 1); thus, the incidence of palatal fistula was $3.1 \%(20 / 636)$. The most common location of fistulas was the hard palate $(9 / 20,45 \%)$. Six cases of fistula were found in the junction of the hard and soft palate $(6 / 20,30 \%)$, and five cases of fistula were found in the soft palate (5/20, 25\%) (Fig. 3). Complete palatal disruption did not occur in any cases.

The incidence of fistula was not significantly associated with sex, age at cleft palate repair, the presence of an associated syndrome, cleft lip, and the extent of the cleft (Table 1). In contrast,
Table 1. Comparison of the incidence of palatal fistula according to various factors

\begin{tabular}{|c|c|c|c|}
\hline Factor & $\begin{array}{l}\text { No. of } \\
\text { patients }\end{array}$ & $\begin{array}{c}\text { No. of } \\
\text { fistula (\%) }\end{array}$ & P-value \\
\hline Patient sex & & & 0.949 \\
\hline Male & 386 & $12(3.1)$ & \\
\hline Female & 250 & $8(3.2)$ & \\
\hline Age at cleft palate repair & & & 0.310 \\
\hline$\leq 18 \mathrm{mo}$ & 503 & $14(2.8)$ & \\
\hline$>18 \mathrm{mo}$ & 133 & $6(4.5)$ & \\
\hline Presence of an associated syndrome & & & 0.865 \\
\hline Non-syndromic & 609 & $19(3.1)$ & \\
\hline Syndromic & 27 & $1(5.9)$ & \\
\hline Associated cleft lip & & & 0.414 \\
\hline Yes & 115 & $5(4.3)$ & \\
\hline No & 521 & $15(2.9)$ & \\
\hline Extent of cleft & & & 0.201 \\
\hline Submucous cleft palate & 72 & $5(6.9)$ & \\
\hline Veau class I & 109 & $4(3.7)$ & \\
\hline Veau class II & 337 & $7(2.1)$ & \\
\hline Veau class III & 86 & $2(2.3)$ & \\
\hline Veau class IV & 32 & $2(6.3)$ & \\
\hline Technique of cleft palate repair & & & $0.042^{\mathrm{al}}$ \\
\hline Busan modification & 298 & $9(3.0)$ & \\
\hline Furlow double opposing Z-plasty & 33 & $4(12.1)$ & \\
\hline Intravelar veloplasty & 11 & 0 & \\
\hline Two-flap & 198 & $4(2.0)$ & \\
\hline Veau-Wardill-Kilner & 96 & $3(3.1)$ & \\
\hline
\end{tabular}

the technique of cleft palate repair significantly predicted the incidence of palatal fistula following cleft palate repair $(\mathrm{P}=0.042)$. Statistical testing was performed to determine whether the technique of cleft palate repair was associated with the incidence of palatal fistula. There was a significantly higher incidence of fistula in patients who underwent surgery using the Furlow double-opposing Z-plasty technique (12.1\%) than in cases where the Busan modification (3.0\%) or two-flap technique (2.0\%) was used (Table 2).

\section{DISCUSSION}

Previous studies have reported a wide range of fistula rates after cleft palate repair, ranging from $0 \%$ to $60 \%$ [8-12]. We report a $3.1 \%$ incidence of palate fistulas, which is lower than that recently reported in the literature. One reason for this difference may be related to the inclusion criteria for the definition of palatal fistula; in particular, we excluded nasal alveolar fistulas and unrepaired primary palatal fistulas. Without a clear definition of palatal fistula, it is difficult to compare the results across studies. Previous studies have reported that high-volume operators produce better outcomes than low-volume operators $[17,18]$. Furthermore, high-volume operators had better results in terms of 
Table 2. Estimated odds ratios for the incidence of palatal fistula: relationships among cleft palate repair techniques

\begin{tabular}{lcc}
\hline & Odds ratio (95\% confidence interval) & P-value \\
\hline Busan modification vs. Furlow double opposing Z-plasty & $4.42(3.00-12.10)$ & $0.02^{2 a}$ \\
Busan modification vs. intravelar veloplasty & $1.30(3.30-0.00)$ & 0.84 \\
Busan modification vs. two-flap & $0.66(3.00-2.00)$ & 0.49 \\
Busan modification vs. Veau-Wardill-Kilner & $1.03(3.00-3.10)$ & 0.95 \\
Furlow double opposing Z-plasty vs. intravelar veloplasty & $0.28(12.10-0.00)$ & 0.41 \\
Furlow double opposing Z-plasty vs. two-flap & $0.14(12.10-2.00)$ & $0.01^{2)}$ \\
Furlow double opposing Z-plasty vs. Veau-Wardill-Kilner & $0.23(12.10-3.10)$ & 0.06 \\
Intravelar veloplasty vs. two-flap & $0.53(0.00-2.00)$ & 0.67 \\
Intravelar veloplasty vs. Veau-Wardill-Kilner & $0.63(0.00-3.10)$ & 0.92 \\
Two-flap vs. Veau-Wardill-Kilner & $1.56(2.00-3.10)$ & 0.05 \\
\hline
\end{tabular}

The odds ratio is the ratio of the odds of failure for the second procedure to that of the first. Values above 1.00 favor the first procedure, whereas values below 1.00 favor the second procedure.

a) Significant values, $P<0.05$
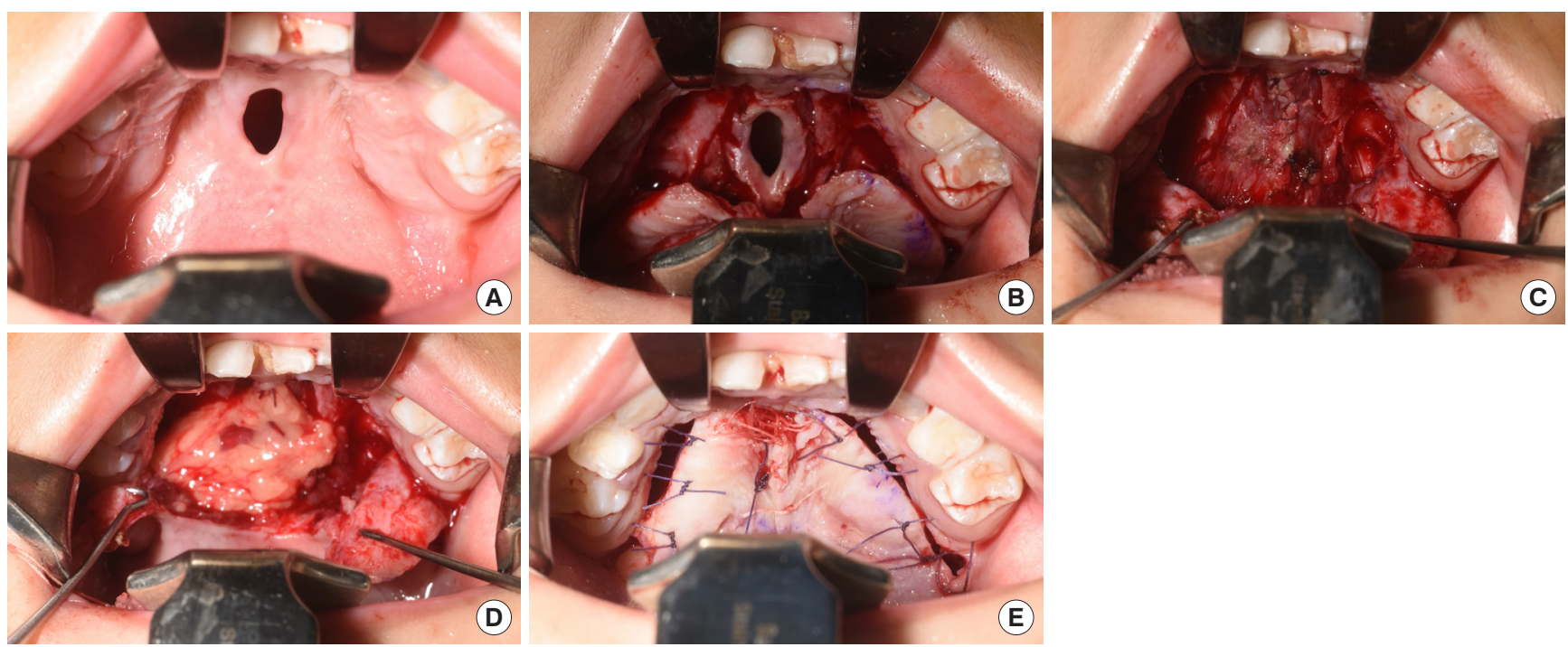

Fig. 4. Surgical treatment using a Veau flap for postoperative palatal fistula. (A) A patient with palatal fistula after cleft palate repair using the Busan modification at the hard palate. (B) Flap elevation for a bilateral Veau flap and turnover flap. (C) After nasal-side mucosa repair. (D) Insertion of a buccal fat pad at the hard palate. (E) Closure of the palatal fistula by a bilateral Veau flap, turnover flap, and buccal fat flap.

dental arch relationships and facial appearance. The surgeon who performed the operations analyzed in this study was a highvolume operator who operated on more than 700 patients over 25 years, which may have contributed to the lower incidence of fistula.

The present study analyzed the location of the fistula, and revealed a greater incidence $(45 \%)$ in the hard palate. Similarly, many studies have reported that palatal fistulas occur more frequently in the anterior region of the palate [19]. It was not possible to examine the size or shape of the fistula due to a lack of information in the records.

All patients with palatal fistula were repaired using a unilateral or bilateral Veau soft tissue flap and turnover flap. In recent procedures, a buccal fat pad flap was additionally performed (Fig. 4). The surgical method used to repair palatal fistula and the recur- rence rate after surgery are under review and will soon be reported.

The optimal age for cleft palate repair is determined based on reduced maxillofacial growth disturbances and favorable speech outcomes. At our hospital, we recommend performing cleft palate repair at the age of 10-18 months. However, there were cases in which the repair was performed after the age of 18 months due to a delayed diagnosis or other medical issues. The mean age at cleft palate repair in the group of patients who underwent cleft palate repair after 18 months was 34 months, and submucosal cleft palate was the most prevalent type (64/133). While some studies have argued that the incidence of fistula is directly proportional to the patient's age at operation $[10,11,20]$, other studies have reported that there was no significant difference in fistula formation between patients younger than 18 months and 
older patients [20]. This study found no significant association between the incidence of palatal fistula and age at the time of cleft palate repair.

Whether cleft palate-related syndrome influences the incidence of palatal fistula after cleft palate repair remains controversial. Stransky et al. [21] reported that the rate of secondary surgery for velopharyngeal insufficiency due to postoperative palatal fistulas was not influenced by the presence of the Pierre Robin sequence. However, Saothonglang et al. [9] reported that cleft associated with syndromes was a predictive factor for fistula formation, and Bresnick et al. [13] reported that patients with Treacher Collins syndrome had a higher likelihood of fistula development than non-syndromic patients. According to our institutional review of palatal repair, 27 patients were syndromic (4.25\%). The associated syndromes were DiGeorge, trisomy 21, Treacher Collins, Cornelia de Lange, Vater, Pierre Robin, Emanuel, and Möbius. The most frequently associated syndrome was Pierre Robin syndrome (40.74\%). No statistically significant association was found between the incidence of palatal fistula and the presence of an associated syndrome.

We chose the Veau classification to evaluate the extent of the cleft, and past studies have reported that the cleft type classified using the Veau system was a predictor of fistula formation. In particular, a higher fistula rate has been reported in patients with Veau classes III and IV [14,19]. Although statistically insignificant $(P=0.201)$, patients with submucous cleft palate and Veau class IV showed a higher incidence of fistula than those with other Veau classification types in our study.

In our study population, a significant association was found between the incidence of palatal fistula and surgical technique, similar to previous findings of an association between the incidence of palatal fistula and the technique of cleft palate repair used. Cohen et al. [14] reported that the Veau-Wardill-Kilner technique was associated with a higher incidence of fistula, while Amaratunga [22] reported that the Von Langenbeck repair was associated with a higher incidence of fistula. In addition, some studies reported that the Furlow double-opposing Zplasty led to a higher incidence of fistula than other surgical techniques [23], while others reported contradictory findings [24]. In this study, we compared the Furlow double-opposing Z-plasty technique with the Busan modification technique and the two-flap technique, neither of which uses Z-plasty for muscle repair. We found that the Furlow double-opposing Z-plasty technique was associated with a high incidence of palatal fistula.

There might be several reasons for this finding. First, the originally introduced double-opposing Z-plasty showed a high fistula rate when used in cases of wide cleft palate because tension occurs at the soft and hard palate junction and midpalatal suture line $[25,26]$. However, several modifications have been introduced to reduce this problem. After LaRossa et al. [27] introduced the Children's Hospital of Philadelphia modification, it became possible to reduce the tension through lateral incision when repairing a wide cleft or even when there is tissue deficiency. Horswell and Chou [28] reported that the fistula rate during surgery using standard Furlow double-opposing Z-plasty was $22.4 \%$, whereas performing the modified Furlow doubleopposing Z-plasty technique reduced the fistula rate to $3 \%$. In this study, these operations were performed using the standard Furlow palatoplasty technique, which may be why the fistula rate was higher than recently reported in studies using Furlow double-opposing Z-plasty. In addition, the surgeon used the Furlow double-opposing Z-plasty technique in earlier procedures to repair the submucosal cleft palate, but gradually transitioned to other techniques due to the high incidence of fistula. Consequently, the number of operations with the Furlow double-opposing Z-plasty technique $(\mathrm{n}=33)$ was smaller than that of procedures performed using the Busan modification ( $\mathrm{n}=$ $298)$ and the two-flap technique ( $n=198)$, suggesting that the surgeon had less experience with the Furlow double-opposing Z-plasty technique. The surgeon's varying levels of experience with different surgical techniques could have affected the incidence of fistula.

Patient and family education is crucial to improving postoperative outcomes. Many studies have reported that the integration of therapeutic education for patients into a clinical pathway approach was helpful in optimizing clinical outcomes [29], and it was also reported that patient and family education lowered the incidence of palatal fistula more than 2-fold [30]. Further, according to our experience, good communication between physicians and patients' parents plays a critical role in reducing the incidence of fistula.

This study had some limitations. First, it was a retrospective, single-center study. Second, we only evaluated a few risk factors; thus, subsequent studies should assess cleft width or severity and surgeon experience. In addition, the patients were not randomized. The uneven distribution of variables (sex, age at the time of cleft repair, presence of an associated syndrome, cleft lip, the extent of the cleft, and the technique of cleft palate repair) among patients makes the interpretation of results of this study more complex. Future studies should be conducted to address these issues.

In summary, the overall incidence of palatal fistula was $3.1 \%$ in this study. Moreover, the technique of cleft palate repair was identified as a predictor of fistula incidence. These results may help raise awareness among craniofacial surgeons regarding the impact of choosing the cleft palate repair technique, especially 
regarding the postoperative incidence of fistula. While surgical techniques are chosen based on the surgeon's preference and experience, the improvement of surgical techniques could lead to better surgical outcomes.

\section{NOTES}

\section{Conflict of interest}

No potential conflict of interest relevant to this article was reported.

\section{Ethical approval}

The study was approved by the Institutional Review Board of Pusan National University Hospital (IRB No. H-2106-017104) and performed in accordance with the principles of the Declaration of Helsinki. The informed consent was waived because this study design is a retrospective chart review.

\section{Patient consent}

The patients' legal guardian provided written informed consent for the publication and the use of patients' images.

\section{Author contribution}

Conceptualization: YC Bae. Data curation: HJ Seo, YC Bae. Formal analysis: HJ Seo. Methodology: MS Park. Writing original draft: MS Park. Writing - review \& editing: HJ Seo.

\section{ORCID}

Min Suk Park

Hyung Joon Seo

Yong Chan Bae

https://orcid.org/0000-0002-4696-7837

https://orcid.org/0000-0003-1111-492X

https://orcid.org/0000-0002-0268-4667

\section{Data availability statement}

The datasets used and/or analyzed during the current study are available from the corresponding author on reasonable request.

\section{REFERENCES}

1. Tanaka SA, Mahabir RC, Jupiter DC, et al. Updating the epidemiology of cleft lip with or without cleft palate. Plast Reconstr Surg 2012;129:511e-518e.

2. Tolarova MM, Cervenka J. Classification and birth prevalence of orofacial clefts. Am J Med Genet 1998;75:126-37.

3. Eliason MJ, Hadford S, Green L, et al. Incidence of fistula formation and velopharyngeal insufficiency in early versus standard cleft palate repair. J Craniofac Surg 2020;31:980-2.

4. Moores C, Shah A, Steinbacher DM. Cleft palate repair using a double opposing Z-plasty.J Craniofac Surg 2016;27:e444-5.
5. van Aalst JA, Kolappa KK, Sadove M. MOC-PSSM CME article: nonsyndromic cleft palate. Plast Reconstr Surg 2008;121(1 Suppl):1-14.

6. Landheer JA, Breugem CC, van der Molen AB. Fistula incidence and predictors of fistula occurrence after cleft palate repair: two-stage closure versus one-stage closure. Cleft Palate Craniofac J 2010;47:623-30.

7. Diah E, Lo LJ, Yun C, et al. Cleft oronasal fistula: a review of treatment results and a surgical management algorithm proposal. Chang Gung Med J 2007;30:529-37.

8. Chouairi F, Mets EJ, Gabrick KS, et al. Veau III and Veau IV cleft palate: do peri-operative complications differ? J Craniofac Surg 2019;30:2372-4.

9. Saothonglang K, Punyavong P, Winaikosol K, et al. Risk factors of fistula following primary palatoplasty. J Craniofac Surg 2021;32:587-90.

10. Sullivan SR, Marrinan EM, LaBrie RA, et al. Palatoplasty outcomes in nonsyndromic patients with cleft palate: a 29year assessment of one surgeon's experience. J Craniofac Surg 2009;20 Suppl 1:612-6.

11. Andersson EM, Sandvik L, Semb G, et al. Palatal fistulas after primary repair of clefts of the secondary palate. Scand J Plast Reconstr Surg Hand Surg 2008;42:296-9.

12. Mak SY, Wong WH, Or CK, et al. Incidence and cluster occurrence of palatal fistula after furlow palatoplasty by a single surgeon. Ann Plast Surg 2006;57:55-9.

13. Bresnick S, Walker J, Clarke-Sheehan N, et al. Increased fistula risk following palatoplasty in Treacher Collins syndrome. Cleft Palate Craniofac J 2003;40:280-3.

14. Cohen SR, Kalinowski J, LaRossa D, et al. Cleft palate fistulas: a multivariate statistical analysis of prevalence, etiology, and surgical management. Plast Reconstr Surg 1991;87:1041-7.

15. Smith DM, Vecchione L, Jiang S, et al. The Pittsburgh Fistula Classification System: a standardized scheme for the description of palatal fistulas. Cleft Palate Craniofac J 2007;44: 590-4.

16. Bae YC, Lee JW, Seo HJ. Modified palatoplasty method (Busan modification) for incomplete type cleft palate. J Craniofac Surg 2015;26:1203-6.

17. Emory RE Jr, Clay RP, Bite U, et al. Fistula formation and repair after palatal closure: an institutional perspective. Plast Reconstr Surg 1997;99:1535-8.

18. Ahmed MK, Maganzini AL, Marantz PR, et al. Risk of persistent palatal fistula in patients with cleft palate. JAMA Facial Plast Surg 2015;17:126-30.

19. Muzaffar AR, Byrd HS, Rohrich RJ, et al. Incidence of cleft palate fistula: an institutional experience with two-stage palatal repair. Plast Reconstr Surg 2001;108:1515-8. 
20. Lu Y, Shi B, Zheng Q, et al. Incidence of palatal fistula after palatoplasty with levator veli palatini retropositioning according to Sommerlad. Br J Oral Maxillofac Surg 2010;48:63740.

21. Stransky C, Basta M, Solot C, et al. Do patients with Pierre Robin sequence have worse outcomes after cleft palate surgery? Ann Plast Surg 2013;71:292-6.

22. Amaratunga NA. Occurrence of oronasal fistulas in operated cleft palate patients. J Oral Maxillofac Surg 1988;46:834-8.

23. Losken HW, van Aalst JA, Teotia SS, et al. Achieving low cleft palate fistula rates: surgical results and techniques. Cleft Palate Craniofac J 2011;48:312-20.

24. Timbang MR, Gharb BB, Rampazzo A, et al. A systematic review comparing Furlow double-opposing Z-plasty and straight-line intravelar veloplasty methods of cleft palate repair. Plast Reconstr Surg 2014;134:1014-22.

25. Furlow LT. The double opposing Z-plasty for palate closure. Part 1. In: Jackson IT, Sommerlad BC, editors. Recent advances in plastic surgery number 4. London: Churchill Livingstone; 1992. p. 29-39.
26. Randall P, LaRossa D, Cohen SR, et al. The double opposing Zplasty for palate closure. Part 2. In: Jackson IT, Sommerlad BC, editors. Recent advances in plastic surgery number 4. London: Churchill Livingstone; 1992. p. 41-4.

27. LaRossa D, Jackson OH, Kirschner RE, et al. The Children's Hospital of Philadelphia modification of the Furlow doubleopposing Z-palatoplasty: long-term speech and growth results. Clin Plast Surg 2004;31:243-9.

28. Horswell BB, Chou J. Does the Children's Hospital of Philadelphia modification improve the fistula rate in Furlow double-opposing Z-plasty? J Oral Maxillofac Surg 2020;78: 2043-53.

29. Searle A, Neville P, Ryan S, et al. The role of the clinical nurse specialist from the perspective of parents of children born with cleft lip and/or palate in the United Kingdom: a qualitative study. Clin Nurse Spec 2018;32:121-8.

30. Sue GR, Deptula PL, Chang J. Surgical team trips to Vietnam: implementation of a dedicated cleft palate perioperative program improves fistula rates. Ann Plast Surg 2021;87: 528-32. 